OPEN ACCESS

Edited by:

Yongxi Song,

The First Affiliated Hospital of China

Medical University, China

Reviewed by:

Reza Ghasemi,

Washington University School of Medicine in St. Louis, United States

Makoto T. Hayashi,

Kyoto University, Japan

*Correspondence:

Johanne Tremblay

johanne.tremblay@umontreal.ca

Specialty section:

This article was submitted to

Cancer Genetics,

a section of the journal

Frontiers in Oncology

Received: 15 December 2020

Accepted: 01 February 2021

Published: 09 March 2021

Citation:

Campion CG, Verissimo T, Cossette S and Tremblay J (2021) Does

Subtelomeric Position of COMMD5 Influence Cancer Progression?

Front. Oncol. 11:642130. doi: 10.3389/fonc.2021.642130

\section{Does Subtelomeric Position of COMMD5 Influence Cancer Progression?}

\author{
Carole G. Campion ${ }^{1,2}$, Thomas Verissimo ${ }^{1,2}$, Suzanne Cossette ${ }^{1}$ \\ and Johanne Tremblay ${ }^{1,2 *}$ \\ ${ }^{1}$ Centre de Recherche, Centre Hospitalier de l'Université de Montréal (CRCHUM), Montréal, QC, Canada, ${ }^{2}$ Département de \\ Médecine, Université de Montréal, Montréal, QC, Canada
}

The COMMD proteins are a family of ten pleiotropic factors which are widely conserved throughout evolution and are involved in the regulation of many cellular and physiological processes. COMMD proteins are mainly expressed in adult tissue and their downregulation has been correlated with tumor progression and poor prognosis in cancer. Among this family, COMMD5 emerged as a versatile modulator of tumor progression. Its expression can range from being downregulated to highly up regulated in a variety of cancer types. Accordingly, two opposing functions could be proposed for COMMD5 in cancer. Our studies supported a role for COMMD5 in the establishment and maintenance of the epithelial cell phenotype, suggesting a tumor suppressor function. However, genetic alterations leading to amplification of COMMD5 proteins have also been observed in various types of cancer, suggesting an oncogenic function. Interestingly, COMMD5 is the only member of this family that is located at the extreme end of chromosome 8, near its telomere. Here, we review some data concerning expression and role of COMMD5 and propose a novel rationale for the potential link between the subtelomeric position of COMMD5 on chromosome 8 and its contrasting functions in cancer.

Keywords: COMMD proteins, COMMD5/HCaRG, kidney cancer, telomere, differentiation, biomarker, cellular senescence

\section{COMMD PROTEINS AND CANCER}

COMMD proteins are part of a large multiprotein complex named Commander that contains up to 15 subunits including the CCC complex: COMMDs (1 to 10) proteins, CCDC22, and CCDC93, and three other components: C16orf62, SH3GLB1, and DSCR3 (1). This complex is highly conserved in vertebrates arguing that it is likely a complex of central importance involved in fundamental cellular function (1-3). COMMDs proteins have been reported in pleiotropic functions including, copper metabolism $(4,5)$, ubiquitination $(6-8)$, hypoxia adaptation $(9,10)$, proinflammatory signaling $(8$, $11,12)$, electrolyte transport (13), and endocytic sorting and recycling of various membrane proteins $(4,14-16)$. Only few studies have directly identified COMMDs proteins as therapeutic target in cancer and most of them reported a downregulation of COMMDs expression in cancer cells, suggested tumor suppressor properties (Figure 1). COMMD1 is the COMMD protein the 


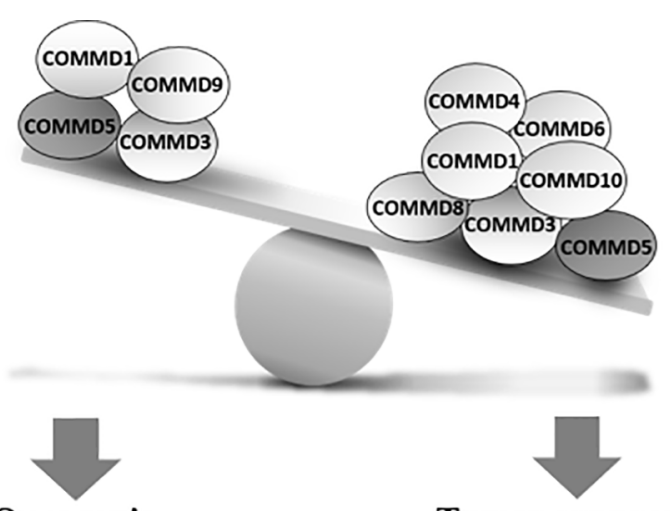

\section{Oncogenic} properties
Tumor suppressor properties

COMMD1
- Lymphoma ${ }^{25 *, 26 * 28 *}$
COMMrectal cancer ${ }^{31 *}$
- Leukemia ${ }^{30 *}$
COMMD5
- Lymphoma ${ }^{27 *}$
- Leukemia $9 *$
- Hepatocellular
carcinoma ${ }^{32 *}$
- Oral squamous cell
carcinoma ${ }^{33 *}$
COMMD9
- Lung cancer ${ }^{24}$
*Study reporting association
between genetic alterations
in COMMD gene and
cancer

\section{COMMD1}

- Ovarian Cancer ${ }^{9,17}$

- $\mathrm{HNSCC}^{20}$

- Prostate cancer ${ }^{9,19}$

- Neuroblastoma ${ }^{18}$

- Colitis associated cancer ${ }^{22}$

- Lung cancer ${ }^{21}$

COMMD3

- Lung cancer ${ }^{24}$

\section{COMMD4}

- Lung cancer ${ }^{24}$

COMMD5

- Renal Cancer ${ }^{15}$

- Gastric cancer ${ }^{34}$

- Lung cancer ${ }^{24}$

COMMD6

- Lung cancer ${ }^{24}$

COMMD8

- Lung cancer ${ }^{24}$

COMMD10

Colorectal cancer ${ }^{23}$

FIGURE 1 | Associated studies to tumor suppressor or oncogenic properties of COMMD proteins. Several studies suggested that COMMD proteins had tumor suppressor properties, especially COMMD1 and COMMD5 that have been the most studied in cancer. Most of these studies reported lower COMMD expression levels in a variety of cancers that correlated with tumor progression. However, a few other publications reported some oncogenic properties and their potential involvement in tumor progression was always associated with chromosomal abnormalities and genetic alterations. Recurrent DNA amplifications and gain of chromosome material at COMMD1, COMMD5, and COMMD3 loci have been reported in various cancers. COMMD5 was the most frequently altered gene among the COMMD members to be associated to tumor progression.

most cited for its relation to cancer and decreased COMMD1 expression is associated with increased tumor invasion and worse survival (9). COMMD1 expression was reduced in ovarian cancer $(9,17)$, neuroblastoma $(18)$, prostate cancer $(9$, 19), head and neck squamous-cell carcinoma (HNSCC) (20), lung cancer (21), and colitis-associated cancer progression (22).
As COMMD1 is a suppressor of both the NF- $\kappa \mathrm{B}$ and HIF pathways which are transcriptional regulator of inflammation that plays an important role in oncogenesis, it is not surprising that COMMD1 expression has been correlated with patients' survival in these different types of cancer (9). In colorectal cancer cells, COMMD10 also targets NF- $\mathrm{KB}$ (p65 subunit) and reduced 
its nuclear translocation, thereby leading to the inactivation of $\mathrm{NF}-\kappa \mathrm{B}$ pathway and cancer cells invasion and metastasis (23). The mRNA expression levels of COMMD3, COMMD4, COMMD5, COMMD6, and COMMD8 were also significantly downregulated in non-small cell lung cancer (NSCLC) cell lines, whereas COMMD9 was up-regulated and promotes the development of NSCLC by interacting with the TFDP1/E2F1 through the COMM domain (24).

Even if most studies related that decreased COMMDs expression was frequently observed in a variety of cancers and correlated with tumor progression, some publications suggested oncogenic properties (Figure 1). Interestingly, their potential involvement in tumor progression was associated to chromosomal abnormalities and genetic alterations. Studies have investigated the genetic basis of variations in gene expression associated with cancer susceptibility by performing whole genome array, single-nucleotide polymorphism array, and next-generation sequencing analyses. Molecular events were identified and associated with increased risk of malignancies, tumor relapse, and poor survival. They identified recurrent DNA amplifications, and gain of chromosomic region mapping the locus of COMMD1, COMMD5, and COMMD3 have been reported in lymphoma (25-28), leukemia (29, 30), colorectal cancer (31), hepatocellular carcinoma (32), and oral squamous cell carcinoma (33).

COMMD5/HCaRG is the second COMMD protein most published in relation to cancer. A down-regulation of COMMD5 has been observed in renal and lung cancer $(15,24)$ and in human gastric cancerous tissue (34). However, we noted that COMMD5 is also the most frequently altered gene among the COMMD member that was associated to tumor progression $(27,29,32,33)$. Surprisingly, these studies observed an amplification of COMMD5 that may paradoxically promote cancer progression.

\section{THE VARIABLE EXPRESSION OF COMMD5 IN CANCER}

Twenty years ago, we identified a novel hypertension-related, calcium-regulated gene, HCaRG, that is overexpressed in different organs of genetically hypertensive strains of rats and whose expression is regulated by extracellular calcium levels with implications in cell proliferation. We mapped its gene on the distal end of human chromosome 8 (35-38). HCaRG was later shown to be COMMD5, the longest protein member of the COMMD family. Our studies demonstrated a role for COMMD5 in the establishment and maintenance of the epithelial cell phenotype, and suggested a tumor suppressor gene function $(15,35,37-41)$. COMMD5 levels are low in various cancer cell lines in rodents and humans (35-38). We found that COMMD5 was underexpressed in human clear-cell renal cell carcinomas (CCRCCc) from 117 patients (39). Its expression was maintained in normal tissues adjacent to small renal tumors, while low expression was observed in normal adjacent tissues of larger size RCCs in patients with poor prognosis. Low COMMD5 levels in normal tissues were associated with worse clinical outcome (recurrence-free survival curves/5 years of patients) (39). COMMD5/HCaRG overexpression inhibited tumor growth and angiogenesis in a homograft renal carcinoma mouse model by promoting de-phosphorylation of ErbB2/HER2, ErbB3/HER3, and EGFR, leading to inhibition of ErbB signaling pathways (39). This suggests that add COMMD5 in a cell which loss its protein may reverse the differentiation state of cell which can return to a more differentiation state. Thus, COMMD5 expression is essential to maintain a differentiated state and events that induce downregulation of COMMD5 may lead to mesenchymal state of the cell.

Interestingly, we also found that COMMD5 chromosomic alteration leading to COMDD5 amplification and overexpression was also associated to cancer progression (Figure 2). To deepen this new paradigm, we analyzed the type and frequency of mutations and copy number alterations (CNV) in the COMMD protein family reported in the cBioPortal database $(42,43)$. This analysis included data from 71,614 samples of different tumor types used in 231 studies. Interestingly, only COMMD2, COMMD5, and COMMD9 presented high rate of genetic alterations ( $>10 \% \mathrm{CNV}$ or mutations) (Figure 2A). COMMD5 alterations have been detected in eight cancer studies, compared to four for COMMD2 and only one for COMMD9. The majority of COMMD5 genetic variations corresponded to amplifications and a very low frequency of gene mutation and deep deletions. High-level amplification of COMMD5 was observed in prostate and ovarian cancers. To determine the impact of COMMD5 amplification on its expression, we selected cancer studies with mRNA expression profiles. We found that copy-number gain of COMMD5 strongly correlated with its mRNA upregulation in prostate and ovarian cancers (Figure 2B). None of the other COMMD members showed high mRNA level in these two types of cancers.

We also screened COMMD5 mutations in the 231 studies used above and evaluated their consequence on COMMD5 functions. Among the 44 reported mutations associated to cancer, 34 were located on sequences specific to COMMD5, and only 10 were within the COMM domain, a highly conserved 70-85 residue C-terminal domain shared by all COMMD members (Figure 2C). We used PolyPhen-2 (Polymorphism Phenotyping $\mathrm{v}$ ) tool and found that $\sim 14 \%$ of mutations in COMMD5 specific region showed a high probability of damaging (high confidence) and $\sim 9 \%$, a potential probability of damaging (lower confidence) COMMD5 function. Among cancer associated to COMMD5 mutations were prostate, breast, lung carcinoma, leukemia, and RCC. We previously showed that COMMD5 is associated to differentiated cell phenotype and is downregulated in different cancer cell lines and $\operatorname{RCC}(38,39)$. We therefore hypothesized that these COMMD5 mutations could disrupt COMMD5 gene or damaged COMMD5 function, leading to malignant cell conversion. Its location on chromosome 8q24, and its crucial role in cellular function makes COMMD5 a putative useful marker of kidney cancer progression and prognosis. Screening for COMMD5 expression levels and somatic mutations in cancer should be initiated. 
A

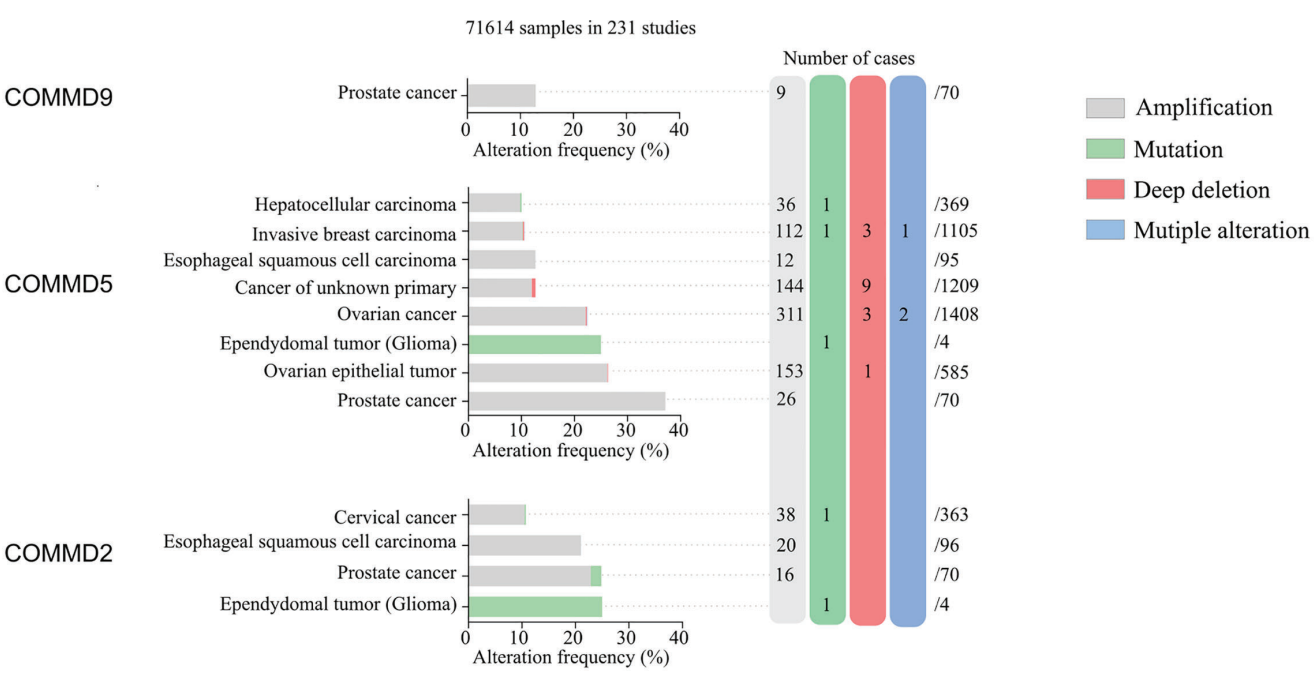

B

Prostate adenocarcinoma

Altered in 24 patients $/ 46$

comMDs [IIIIIIIIIIIIIIIIIIIII!

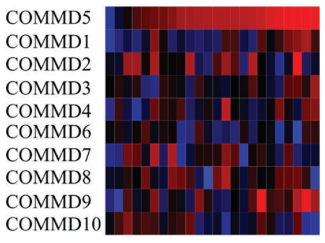

-Alteration frequency $(\%)$

Genetic alteration

|Amplification | Deep deletion || Missense mutation || No alteration

Ovarian cancer

Altered in 113 patients $/ 316$

|

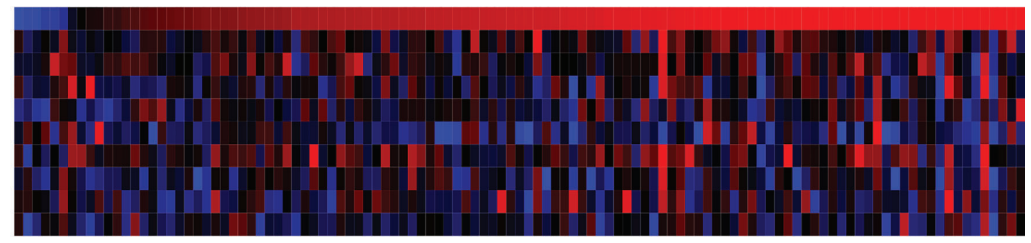

Expression heatmap

$-3 \longrightarrow+3$

【mRNA upregulation

] mRNA downregulation

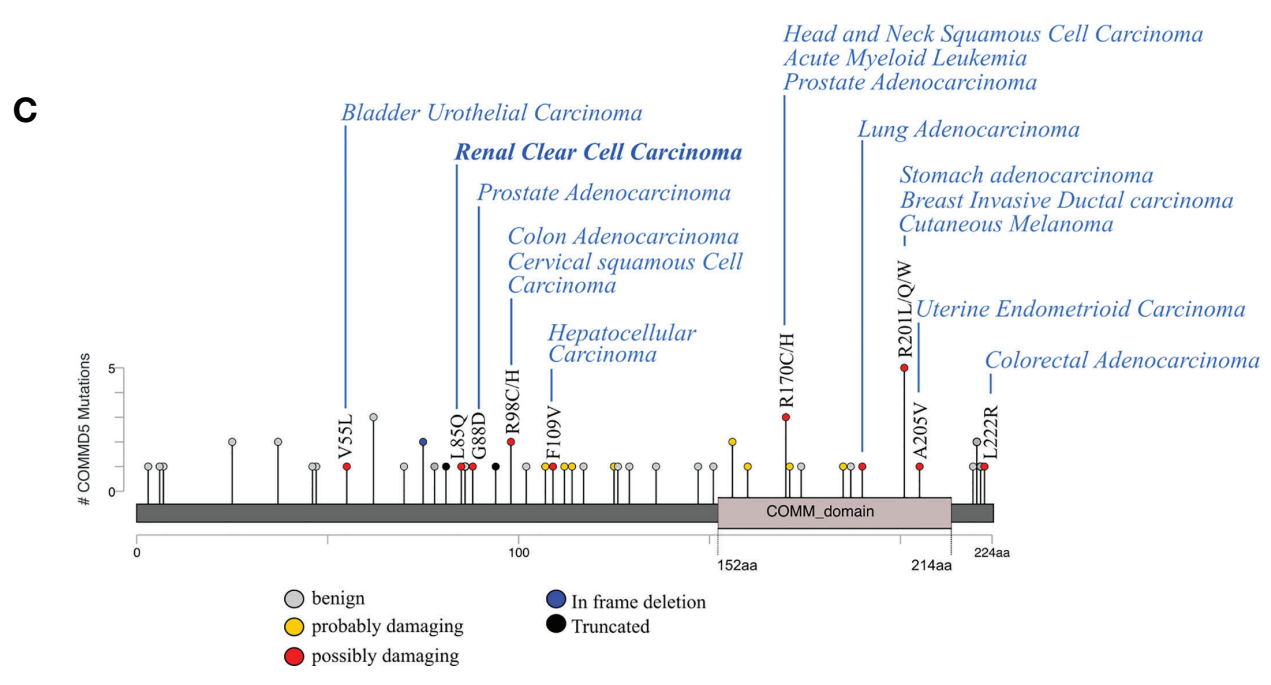

FIGURE 2 | Genetic alterations and tissue expression profile of COMMD proteins and their association to different types of carcinoma. (A) cBioportal database was used to analyze mutations and copy number alterations of COMMD proteins in 231 studies (71,641 samples). Only COMMD2, COMMD5, and COMMD9 presented $>10 \%$ CNV or mutations and were described in this figure. Genetic alterations of COMMD5 in different types of cancer showed the highest frequency of alterations in prostate and ovarian cancers. (B) Heatmap and copy number variations of COMMD proteins in ovarian cancer and prostate adenocarcinoma TCGA data $(\mathrm{n}=46$ and $\mathrm{n}=316$, respectively) obtained from cBioPortal. (C) Graphical summary of COMMD5 mutations from TCGA carcinoma studies mapped across the gene. 
Thus, these data suggest that both COMMD5 downregulation and upregulation may lead to cancer progression, leading us to propose some hypothesis that may explain this paradox.

\section{THE UNIQUE COMMD5 SUBTELOMERIC POSITION}

Among the COMMD family, COMMD5 is the only one located at the extreme end of chromosome 8, 8q24.3 (Figure 3). COMMD5 is the fourth coding protein before the end of the chromosome. In order to explain the variable levels of expression of COMMD5 in cancer, we assessed whether its localization at the end of chromosome 8 could regulate its level of expression in different cancers and during ageing process.

\section{CHROMOSOME 8Q24.3 ALTERATIONS AND CANCER SUSCEPTIBILITY}

Genome wide association studies (GWAS) have identified a large number of single nucleotide polymorphisms (SNPs) and the majority of common risk alleles discovered to date map outside of known protein coding regions (e.g., intronic and intergenic regions). However, a particularly interesting set of risk loci is clustered within the $8 \mathrm{q} 24$ region (chr.8q24) and is linked to susceptibility to different cancers including kidney (44), prostate (45-47), breast (48-50), gastric (51), colon (52-54), ovarian (55, 56), bladder (57), and chronic lymphocytic leukemia (58). In addition, the 8q24 region has recently been identified in a largescale study across human cancers as the most frequently amplified region (59). One gene found within this chr.8q24 region, MYC, is the most frequently amplified protein-coding gene across all cancer types (59).

Few genetic studies have related copy number variants (CNV) and COMMD5 transcripts to cancer progression. Using Affymetrix SNP 6.0 and Affymetrix GeneChip Human Gene 1.0 ST arrays, Peng et al. have identified recurrent DNA amplifications scattered from $8 \mathrm{q} 22.2$ to $8 \mathrm{q} 24.3$ in 112 Oral Squamous Cell Carcinoma (OSCC) specimens (33). COMMD5 was a gene within these amplicons that might be critical to OSCC progression and these DNA amplifications significantly associated with poor survival, and possible early development of second primary tumors. In an integrative genomic analysis of a large series of patients with fibrolamellar hepatocellular carcinoma (FLC) using next-generation sequencing, SNP-array and whole-transcriptome analysis, the most frequent focally amplified locus was at $8 \mathrm{q} 24.3$ in $4 / 32$ patients $(12.5 \%)$ spanning several genes including COMMD5 (32). Highresolution cytogenetic techniques that combine laser capture micro-dissection with microarray-based comparative genomic hybridization technology have provided new opportunities to investigate genome-wide DNA alterations in limited-sized

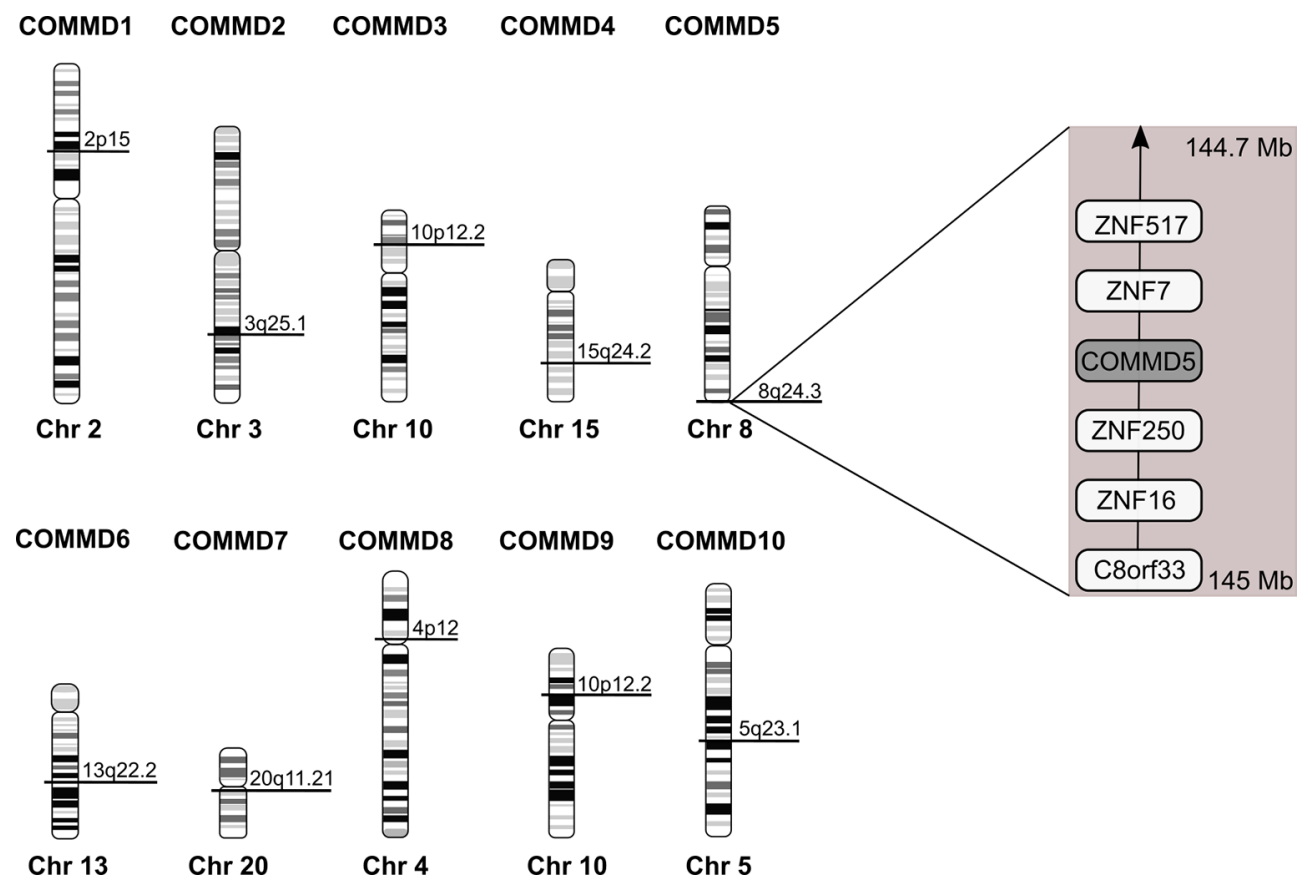

FIGURE 3 | Chromosomal location of the human COMMD family members. Location of COMMD genes was deduced from the homo sapiens genome view of the National Center for Biotechnology Information (Gene ID: 150684 for COMMD1; 51122 for COMMD2; 23412 for COMMD3; 54939 for COMMD4; 28991 for COMMD5; 170622 for COMMD6; 149951 for COMMD7; 54951 for COMMD8; 29099 for COMMD9 and 51397 for COMMD10). COMMD5 is the only COMMD family member located at the extreme end of chromosome. According to The Human Protein Atlas database, COMMD5 is the fourth protein-coding gene from the end of $8 \mathrm{q} 24.3$ chromosome. 
lesions $(60,61)$. Using these technologies, Slovak et al. compared the Hodgkin lymphoma molecular karyotypes to the genomic profiles of germinal center B cells and treatment outcome (chemotherapy responsive vs. primary refractory disease) (27). Among the most frequent gains (>65\%), they identified the 8 q24.3 region which includes genes associated with growth and proliferation. Among them, COMMD5 was identified. Finally, a recent study examined copy number aberrations in the subtelomeric regions of a patient with de novo acute monocytic leukemia (29). This study reported that COMMD5 locus was in the thirty one out of 92 subtelomeric regions (33.7\%) which had duplications between 141,682 and 864,400 bp in size.

Gain of 8q24 region is frequently observed in genome wide association studies (GWAS) of cancer. Through its position on chromosome 8q24.3, COMMD5 is clearly a target for copynumber alterations, and thus a candidate gene for cancer susceptibility. Indeed, using cbioportal database (42, 43), we analyzed COMMD5 mRNA expression relative to normal samples (non-cancerous samples) in several cancer types using the data generated by the Cancer Genome Atlas (TCGA). This analysis included data from 10,967 samples of different human tumor types used in 32 studies. Firstly, we did a correlation analysis between COMMD5 mRNA expression and COMMD5 genetic alterations (Figure 4A). The plot analysis showed that occurrence of COMMD5 amplification is frequently observed in most of cancer types and particularly in breast invasive carcinoma, oesophagus, liver, uterine, and renal cancers, where this amplification correlated with high level of COMMD5 mRNA expression (more than five-fold relative to normal samples). We also found that several shallow deletions and some deep deletions correlated with COMMD5 mRNA downregulation and this is more pronounced in breast invasive carcinoma, colorectal, lung and renal cancer including ccRCC and chromophobe RCC (Figure 4A). We next investigated the relationship between COMMD5 mRNA expression (over or under-expression) and chromosome $8 \mathrm{q}$ alterations including $8 \mathrm{q}$ amplification ("gained") or 8q deletion ("lost") in these tumors (Figure 4B). Interestingly, gain of chromosome $8 \mathrm{q}$ were noted in cancers with higher levels of COMMD5 mRNA, including breast invasive carcinoma, oesophagus, liver, and uterine cancers. Furthermore, downregulation of COMMD5 expression correlated with 8q loss in invasive breast cancer, colorectal and lung cancers and in ccRCC and chromophobe RCC.

Altogether these data support our hypothesis that COMMD5 expression may be influenced by chromosome $8 \mathrm{q}$ alterations, thus, we next investigated whether its proximity to telomere could influence the up- as well as downregulation of COMMD5 gene expression levels.

\section{IS COMMD5 EXPRESSION CONTROLLED BY ITS SUBTELOMERIC POSITION?}

The extreme ends of eukaryotic chromosomes, the telomeres, are special structures that provide protection from enzymatic enddegradation and are crucial in the maintenance of chromosome integrity and genomic stability (62). During cell division throughout life, telomeres are progressively shortened and when telomeres reach a threshold length, a DNA damage response is triggered, leading cells to enter in senescence or in apoptosis $(63,64)$.

Firstly, it is tempting to propose that COMMD5 functions could be related to the subtelomeric position of its gene as studies suggested that telomere length influences cell differentiation (62, 65). In this context, our previous studies demonstrated that COMMD5 plays an essential role in the establishment and maintenance of the epithelial cell phenotype (35-38). Furthermore, we showed that COMMD5 overexpression in kidneys accelerated tubular repair after ischemic injury of transgenic mice by modulating renal cell proliferation and migration, and by facilitating their re-differentiation $(40,41)$. This is in line with Westhoff et al. who demonstrated that short telomeres are associated with an increased renal injury and decreased recovery (66). Hirashima et al. (62) used PC-3 (prostate cancer) cells exhibiting short telomeres and forced their elongation by enhancing cellular telomerase activity. They observed that telomere elongation in these cells resulted in the formation of duct-like structures and well-differentiated tumors in vivo. We analyzed COMMD5 mRNA expression in this study by using data from Gene expression omnibus (GEO) profile GSE41559 (Figure 5). In most cases, COMMD5 expression inversely correlated with the expression of $\mathrm{N}$-cadherin, a mesenchymal marker and with STAT1, an immune responserelated gene in the tumor microenvironment while COMMD9 expression, whose chromosomic location is not in telomeres did not correlate with cancer cell differentiation status. This novel observation showed that high levels of COMMD5 correlated with 1) telomere elongation (by hTERT overexpression and by hTERT+CRE), and 2) cell differentiation induced by telomere elongation. Pucci et al. (65) also showed that functional telomeres are important for the stability of stem cell differentiation as short telomeres in embryonic stem cells led to unstable differentiation. Cancer cells maintain shorter telomeres than the cells in the surrounding normal tissues to sustain their undifferentiated state. We have shown that higher COMMD5 protein levels in normal tissue surrounding RCC tumors favored their differentiated phenotype, reduced tumor growth and enlargement, and correlated with survival rate and better prognosis of patients with RCC (39). Interestingly, many studies observed shorter telomere length in RCC tumors compared with paired normal tissue (67-72). Pal et al. (73) analyzed 100 cases of RCC for telomerase activity and found that RCC tissues had significantly shorter telomere length than the adjacent normal parenchyma. They also found a correlation between telomere length and grades $(\mathrm{p}=0,016)$ of ccRCC but not with its stages $(0,20)$ or subtypes $(p=0,67)$ : low-grade tumors had significantly longer telomeres than high grades which correlated with reduced telomere length. Furthermore, shortening of telomeres has been shown to contribute to renal abnormalities including, glomerular senescence, impaired potassium clearance, renal cysts, fibrosis, glomerulosclerosis, and renal cell carcinomas (74). 
A

Correlation between $C O M M D 5$ mRNA expression relative to normal samples and COMMD5 genetic alterations

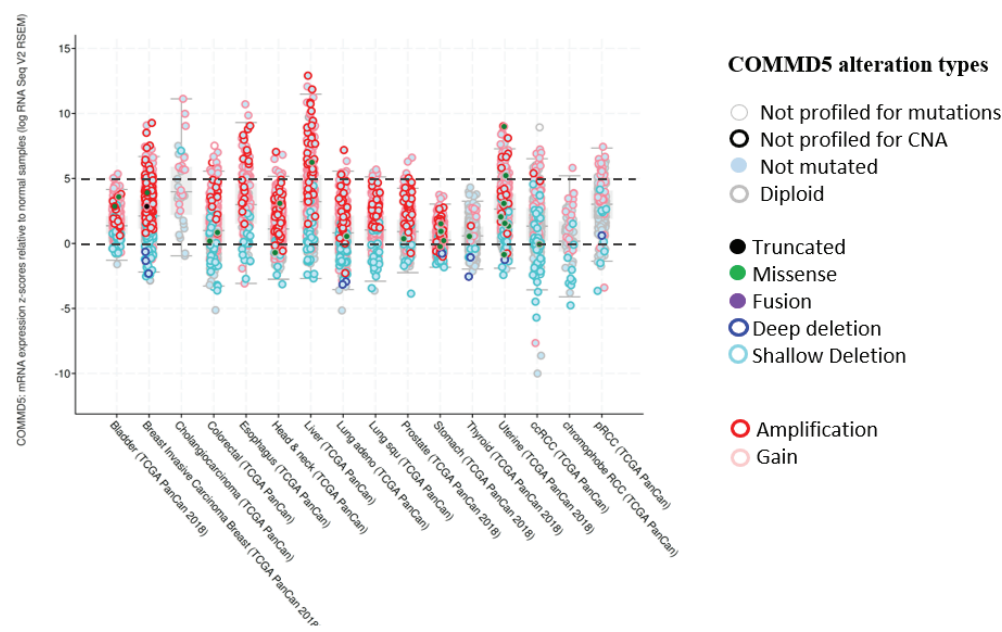

B

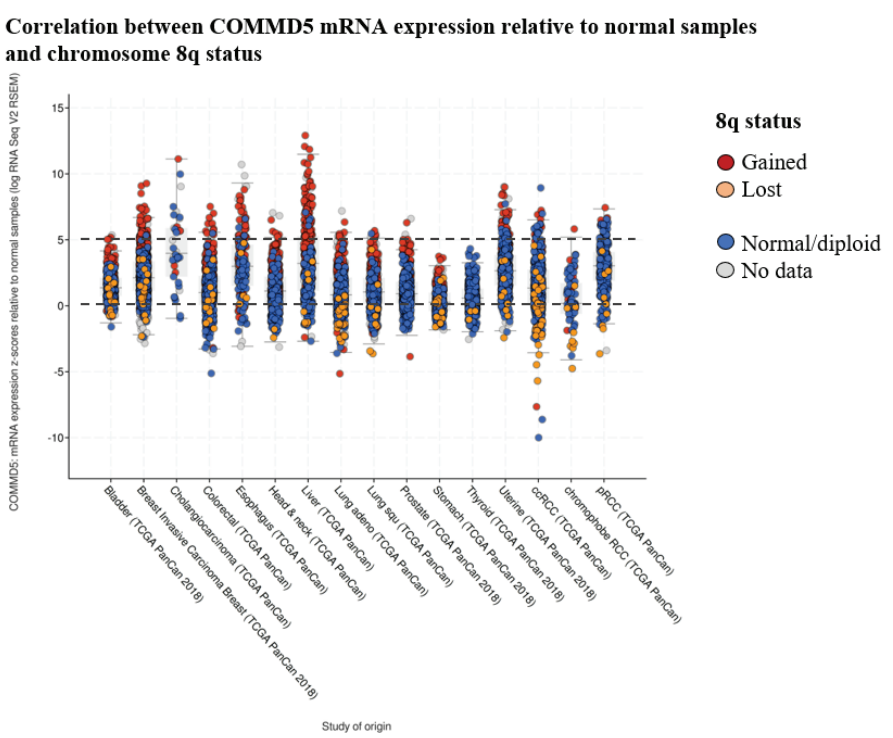

FIGURE 4 | Correlation between COMMD5 mRNA expression relative to normal samples and COMMD5 genetic alterations or chromosome 8q status in several cancer types. cBioportal database $(42,43)$ was used to analyze COMMD5 mRNA expression relative to normal samples in several cancer types using data generated by the Cancer Genome Atlas (TCGA). This analysis included data from 10,967 samples of different human tumor types used in 32 studies. (A) Plot showing correlation between COMMD5 mRNA levels relative to normal samples and COMMD5 genetic alteration in several cancer types. As indicated in the cBioportal database: Deep deletion indicates a deep loss, possibly a homozygous deletion; Shallow deletion indicates a shallow loss, possibly a heterozygous deletion; Gain indicates a low-level gain (a few additional copies, often broad); Amplification indicates a high-level amplification (more copies, often focal). (B) Plot showing correlation between COMMD5 mRNA expression relative to normal samples and chromosome 8q status in several cancer types (including 8q amplification "gained", 8q deletion "lost", no changes in 8q status "normal diploid" and no data). Abbreviations: Lung adeno, lung adenocarcinoma; Lung squ, lung squamous cell carcinoma; ccRCC, clear cell renal cell carcinoma; pRCC, papillary renal cell carcinoma.

Secondly, although telomere shortening can lead to genetic instability and is often correlated with the onset of diseases and cancers, many studies have provided evidence that long telomeres can also contribute to cancer development $(75,76)$. Indeed, even if telomere attrition imposes a barrier to cell proliferation, some cancers developed an adaptative response and can bypass DNA damage response pathways and cellular senescence by upregulating telomerase, a cellular ribonucleoprotein enzyme complex whose function is to elongate telomeres (77). Thus, the association between telomere length and the risk of cancer remains conflicting and these observations suggest that telomeres may play diverse roles in different type of cancers. In renal cancer, Morais et al. proposed that telomeres may play a dual role during RCC carcinogenesis; in the early stages, short telomeres may increase RCC risk and in late carcinogenesis, long telomeres seem to be associated with bad tumor prognosis (71). Using a large series of colorectal cancers, Rampazzo 


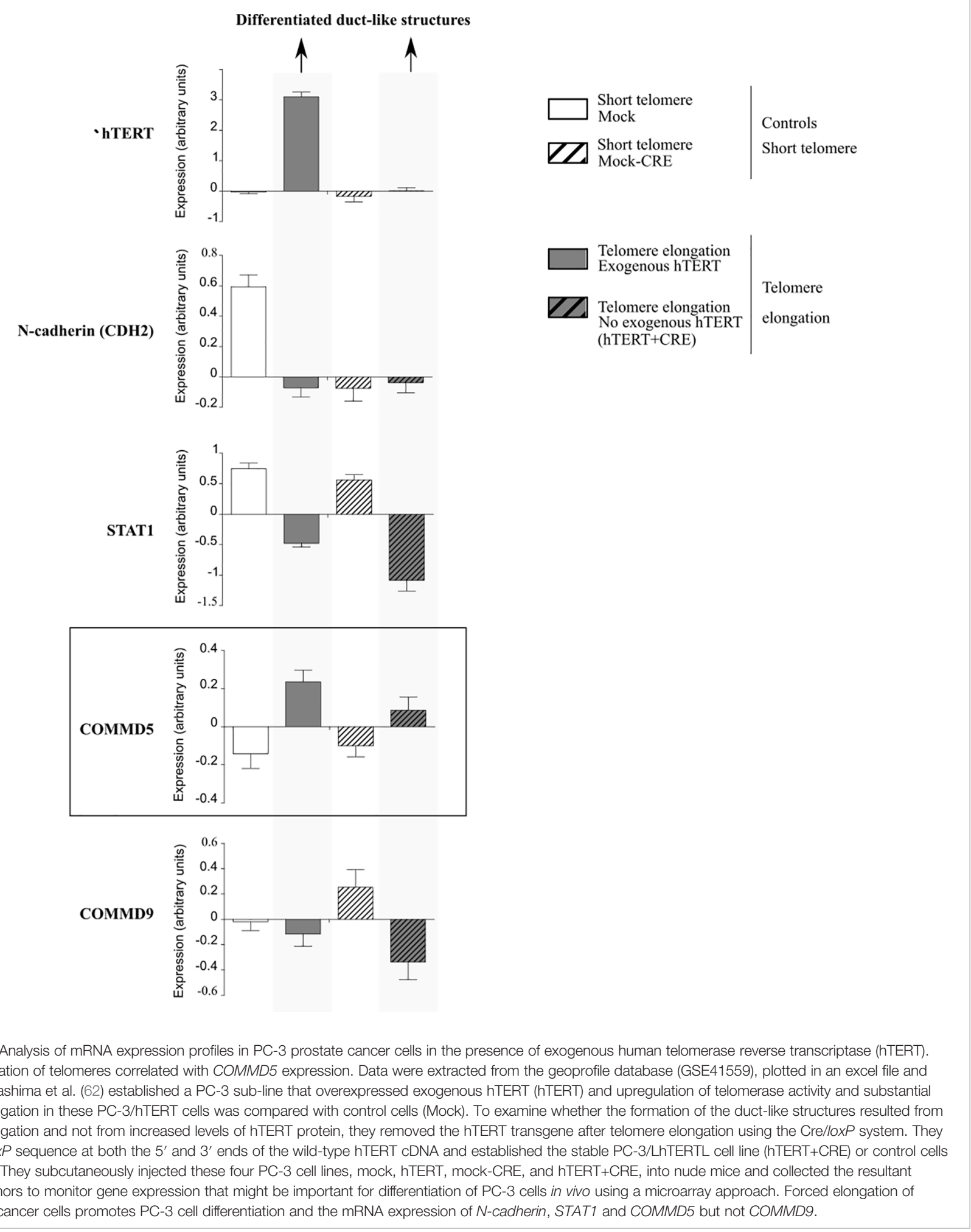

FIGURE 5 | Analysis of mRNA expression profiles in PC-3 prostate cancer cells in the presence of exogenous human telomerase reverse transcriptase (hTERT). Forced elongation of telomeres correlated with COMMD5 expression. Data were extracted from the geoprofile database (GSE41559), plotted in an excel file and analyzed. Hirashima et al. (62) established a PC-3 sub-line that overexpressed exogenous hTERT (hTERT) and upregulation of telomerase activity and substantial telomere elongation in these PC-3/hTERT cells was compared with control cells (Mock). To examine whether the formation of the duct-like structures resulted from telomere elongation and not from increased levels of hTERT protein, they removed the hTERT transgene after telomere elongation using the Cre/loxP system. They added the loxP sequence at both the $5^{\prime}$ and $3^{\prime}$ ends of the wild-type hTERT cDNA and established the stable PC-3/LhTERTL cell line (hTERT+CRE) or control cells (Mock-CRE). They subcutaneously injected these four PC-3 cell lines, mock, hTERT, mock-CRE, and hTERT+CRE, into nude mice and collected the resultant xenograft tumors to monitor gene expression that might be important for differentiation of PC-3 cells in vivo using a microarray approach. Forced elongation of telomeres in cancer cells promotes PC-3 cell differentiation and the mRNA expression of N-cadherin, STAT1 and COMMD5 but not COMMD9.

et al. demonstrated that telomere length varies not only with tumor stage but also differs according to tumor location, being longer in rectal cancers $(p=0.03)$ (78). They also demonstrated that telomeres were significantly shorter in colorectal than in adjacent non-cancerous tissues, regardless of tumor stage, grade, site, or genetic alterations. Hence, they proposed that the different telomere lengths in cancers may be due to different kinetics of telomere erosion/stabilization. 
Considering these observations, we propose that the variability of telomere length in different type of cancers could explain the variable expression of COMMD5 in cancers. This hypothesis is strengthened by the concept of telomere position effects over long distances, TPE-OLD, a mechanism by which gene expression is modulated by telomere length dependent loops (79-82). These telomere loop structures bring genes in direct proximity to the telomeres and can extend to at least 10 $\mathrm{Mb}$ from the chromosome end. Studies demonstrated that TPEOLD induces a local modification of chromatin organization leading to transcriptional changes of genes in close proximity to the loop $(80,83,84)$. This phenomenon is explained by the fact that TPE-OLD involve chromatin modifications (acetylation, methylation) and chromatin remodeling factors that influence gene in direct proximity to this telomere loop (85-89). Upon telomere shortening, looping diminishes, separating the TPEOLD genes from the telomere and its chromatin signature, inducing a new transcriptional modulation of neighboring genes (79). Loop disruption occurs long before telomere shortening induces DNA damage responses.

Thus, TPE-OLD is an active mechanism that participates in the regulation of gene expression by upregulating or downregulating their expression. We suggest that TPE-OLD could be one of the mechanisms responsible for differential transcriptional levels of COMMD5 in cancer.

\section{COULD COMMD5 SUBTELOMERIC POSITION INFLUENCE CELL SENESCENCE?}

It has been proposed that when telomeres shorten to a critical point, a signal is sent to stop further cell division, the hallmark of cellular senescence. The subtelomeric position of COMMD5 raises the question whether loss of COMMD5 after telomere shortening could participate to cellular senescence. Cellular senescence refers to the irreversible arrest of cell proliferation (growth) $(64,90)$. We reported previously $(15)$ that proliferation of renal cell lines (HK-2) depleted of COMMD5 by specific siRNA, is stopped without DNA fragmentation or cell mortality. Morphological change is one of the featured characteristics of senescence. Morphological changes that accompany replicative senescence are increased in cell, nuclear, and nucleolar size, presence of multinucleated cells, prominent Golgi apparati, higher number of vacuoles in the endoplasmic reticulum and cytoplasm, more cytoplasmic microfilaments, and large lysosomal bodies $(91,92)$. Size of senescent cells could be twice as much as non-senescent ones (93). We found that COMMD5 loss induced important morphological changes including higher number of cytoplasmic vacuoles, a rounded cell shape with a doubled cell size and 1.5 fold larger cell nucleus [Figure 6 and (15)]. In addition, COMMD5 depletion led to a strong

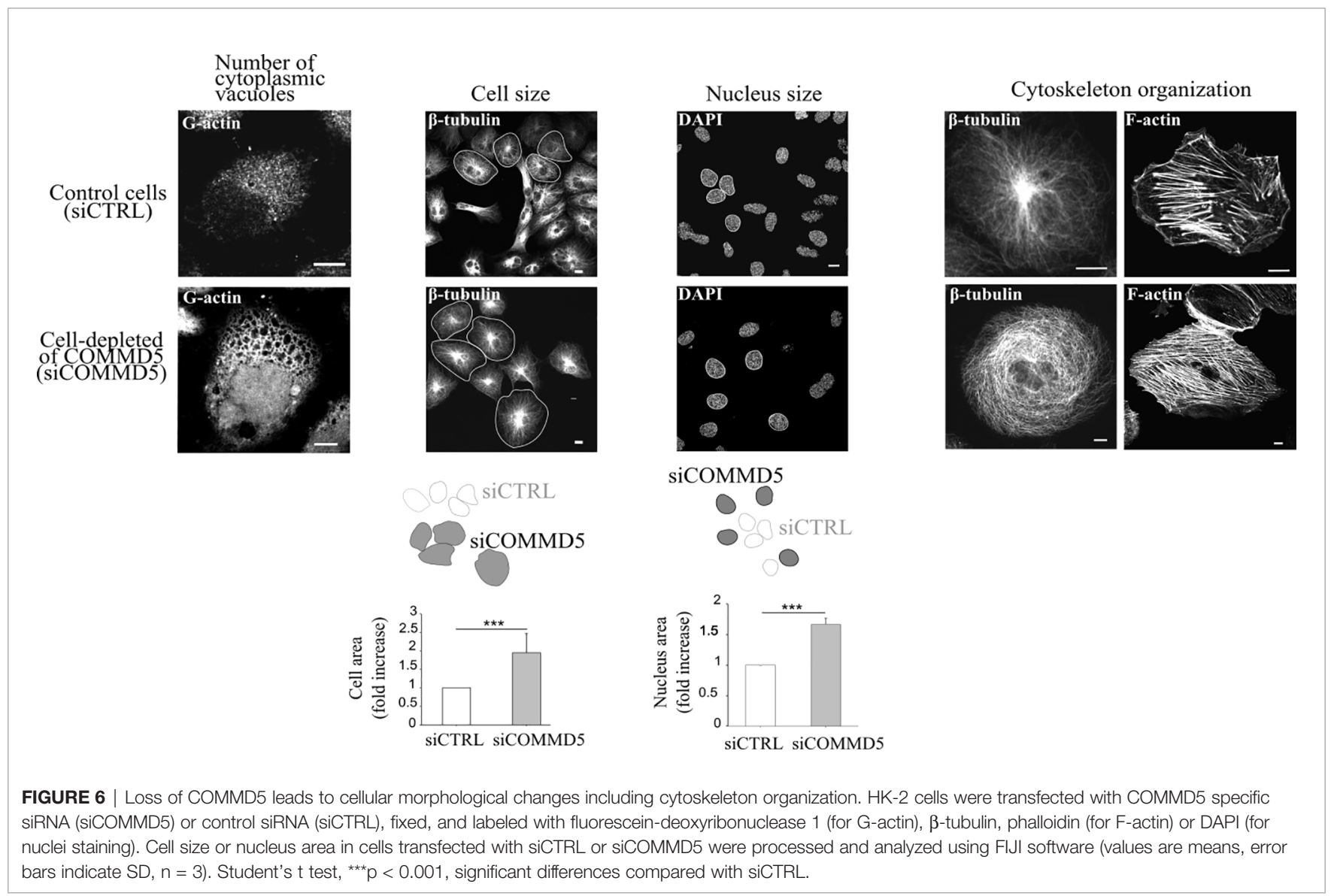


cytoskeletal re-organization with an enrichment of actin stress fibers and a disorganized distribution of microtubules that lose their orientation and acquire an equal radial distribution [Figure 6 and (15)]. These characteristics have also been reported by Xu et al. (94) who showed that miR-22 repressed cancer progression by inducing cellular senescence. They found a significant difference in cell size (up to 1.6-fold) between senescent cells induced by miR-22treatment and control cells. In addition, miR-22-treated cells contained larger actin stress fibers and the authors proposed that miR-22-induced senescence morphology in cancer cells reduced cell motility and invasion. They also observed that senescent fibroblasts and Lenti-Pre22-infected cancer cells exhibited large flattened senescence-like morphology that reduced cell movement. We have also observed these features after COMMD5 depletion in human kidney (HK-2) cell lines. COMMD5-depleted cells had flattened and enlarged cell shapes and exhibited a random migration with most of them spinning around themselves [Video S8 in supplemental information of (15)]. Cells depleted of COMMD5 lost their directional movement leading to a shorter distance of migration and reduced cell motility. As also observed by $\mathrm{Xu}$ et al. (94) in their study, the strong accumulation of actin stress fibers in the cortical region and the loss of microtubule orientation detected in COMMD5-depleted cells probably caused their rounded shape, thus abolishing their directional movement.

Senescence is a stress response that can be induced by a wide range of intrinsic and extrinsic insults, including oncogenic activation, oxidative stress, telomere shortening, etc. (63). In this later event, a DNA damage response is first necessary before cells enter into an early senescence phase. However, COMMD5 subtelomeric position combining to TPE-OLD mechanism could

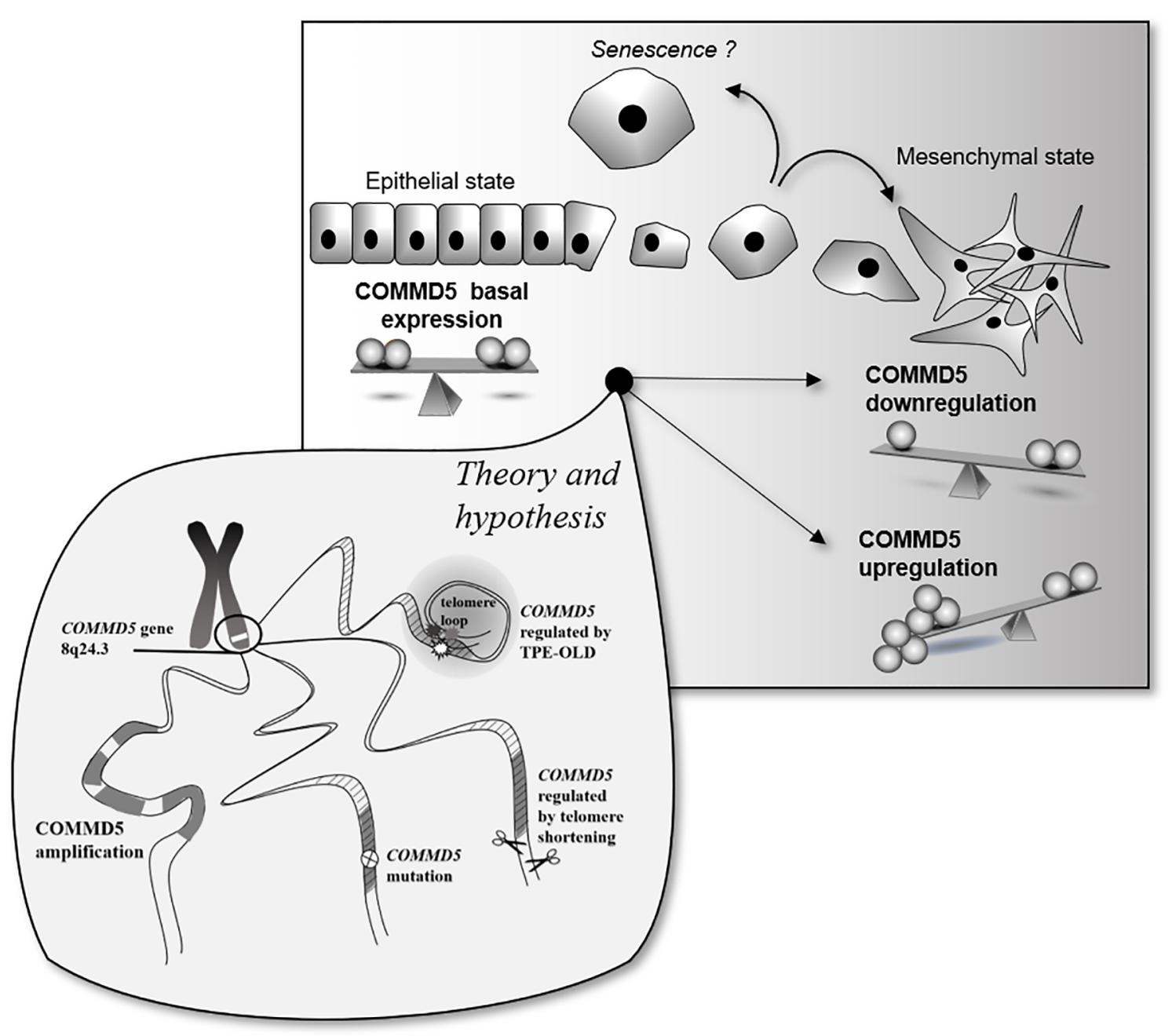

FIGURE 7 | Schematic representation of putative COMMD5 expression profile and cell status. COMMD5/HCaRG plays an essential role in the establishment and maintenance of the epithelial cell phenotype. Downregulation of COMMD5 or complete loss of COMMD5 expression or function by mutations induce an epithelial to mesenchymal transition. On the other hand, too much of COMMD5 is also deleterious to cells. COMMD5 is localized at the extreme end of the chromosome 8 , a region highly targeted by locus amplification. We propose here that its subtelomeric localization could explain the variable expression of COMMD5 in cancer. Gene amplification, mutation, and proximity to telomere are all events that may contribute to regulation of COMMD5 expression in cancer. Consequently, as COMMD5 is involved in crucial cellular functions such as cell differentiation, proliferation, and migration, expression of this gene must be tightly controlled. 
create a favourable environment for the downregulation of COMMD5 and induction of senescent-like features in cells long time before cells inducing a DNA damage response.

\section{CONCLUSION}

The novel observation that COMMD5 expression could be differently regulated in cancer cells by its locus alterations, amplifications, mutations or by telomere length, raises several questions with regards to its function and association to cancer. Is COMMD5 overexpression or downregulation good or bad? Is COMMD5 an oncogenic factor or a tumor suppressor gene? Is COMMD5 a promising therapeutic target for cancer therapy? COMMD5 is expressed in all epithelial tissues and we previously found that its basal expression is essential to maintain a differentiated cell phenotype. The data presented here demonstrate the duality of COMMD5 expression from down to upregulation, but both correlating with cancer susceptibility. Molecular mechanisms that modulate COMMD5 expression in cancer have not yet been elucidated, offering a wide range of possibilities. Here, we focused on the localization of COMMD5 at the subtelomeric position of the chromosome and developed a rationale that this could impact on COMMD5 gene regulation in cancer cells. We showed that COMMD5 gene expression could be affected by different chromosomal events including gene amplification, mutation and telomere length. Upregulation or downregulation of COMMD5 expression by one of these events may elicit cells to undergo mesenchymal transition or even, to acquire senescence-like phenotype. Occurrence of these different events may vary according to tumor type, stage and location. In conclusion, as COMMD5 is involved in carcinogenesis probably by regulating cell differentiation and playing crucial roles in

\section{REFERENCES}

1. Mallam AL, Marcotte EM. Systems-wide Studies Uncover Commander, a Multiprotein Complex Essential to Human Development. Cell Syst (2017) 4:483-94. doi: 10.1016/j.cels.2017.04.006

2. Burkhead JL, Morgan CT, Shinde U, Haddock G, Lutsenko S. COMMD1 forms oligomeric complexes targeted to the endocytic membranes via specific interactions with phosphatidylinositol 4,5-bisphosphate. J Biol Chem (2009) 284:696-707. doi: 10.1074/jbc.M804766200

3. Healy MD, Hospenthal MK, Hall RJ, Chandra M, Chilton M, Tillu V, et al. Structural insights into the architecture and membrane interactions of the conserved COMMD proteins. Elife (2018) 7:e35898. doi: 10.7554/eLife.35898

4. Phillips-Krawczak CA, Singla A, Starokadomskyy P, Deng Z, Osborne DG, Li $\mathrm{H}$, et al. COMMD1 is linked to the WASH complex and regulates endosomal trafficking of the copper transporter ATP7A. Mol Biol Cell (2015) 26:91-103. doi: 10.1091/mbc.e14-06-1073

5. van De Sluis B, Rothuizen J, Pearson PL, van Oost BA, Wijmenga C. Identification of a new copper metabolism gene by positional cloning in a purebred dog population. Hum Mol Genet (2002) 11:165-73. doi: 10.1093/ hmg/11.2.165

6. Drevillon L, Tanguy G, Hinzpeter A, Arous N, de Becdelievre A, Aissat A, et al. COMMD1-mediated ubiquitination regulates CFTR trafficking. PLoS One (2011) 6:e18334. doi: 10.1371/journal.pone.0018334

7. Ganesh L, Burstein E, Guha-Niyogi A, Louder MK, Mascola JR, Klomp LW, et al. The gene product Murrl restricts HIV-1 replication in resting CD4+ lymphocytes. Nature (2003) 426:853-7. doi: 10.1038/nature02171 wound healing or tissue regeneration, its expression must be tightly regulated and controlled. So, small differences in COMMD5 expression could induce variations in cancer susceptibility, and its functional properties are strongly related to its level of expression (Figure 7).

\section{DATA AVAILABILITY STATEMENT}

Publicly available datasets were analyzed in this study. This data can be found here: https://www.cbioportal.org/.

\section{AUTHOR CONTRIBUTIONS}

CC conceived, designed, performed the figures and data analyses, and wrote the manuscript. JT, SC, and TV critically reviewed the manuscript and JT supervised its achievement. All authors contributed to the article and approved the submitted version.

\section{FUNDING}

Our study was funded by the Canadian Institutes of Health Research (CIHR) (grant MOP-133690) to JT. CC was supported by a KRESCENT postdoctoral fellowship.

\section{ACKNOWLEDGMENTS}

The authors would like to thank Professor Pavel Hamet for his critical review of the manuscript.

8. Maine GN, Burstein E. COMMD proteins: COMMing to the scene. Cell Mol Life Sci (2007) 64:1997-2005. doi: 10.1007/s00018-007-7078-y

9. van de Sluis B, Mao X, Zhai Y, Groot AJ, Vermeulen JF, van der Wall E, et al. COMMD1 disrupts HIF-1alpha/beta dimerization and inhibits human tumor cell invasion. J Clin Invest (2010) 120:2119-30. doi: 10.1172/JCI40583

10. van de Sluis B, Muller P, Duran K, Chen A, Groot AJ, Klomp LW, et al. Increased activity of hypoxia-inducible factor 1 is associated with early embryonic lethality in Commd1 null mice. Mol Cell Biol (2007) 27:4142-56. doi: 10.1128/MCB.01932-06

11. Burstein E, Hoberg JE, Wilkinson AS, Rumble JM, Csomos RA, Komarck CM, et al. COMMD proteins, a novel family of structural and functional homologs of MURR1. J Biol Chem (2005) 280:22222-32. doi: 10.1074/jbc.M501928200

12. Starokadomskyy P, Gluck N, Li H, Chen B, Wallis M, Maine GN, et al. CCDC22 deficiency in humans blunts activation of proinflammatory NFkappaB signaling. J Clin Invest (2013) 123:2244-56. doi: 10.1172/JCI66466

13. Biasio W, Chang T, McIntosh CJ, McDonald FJ. Identification of Murr1 as a regulator of the human delta epithelial sodium channel. J Biol Chem (2004) 279:5429-34. doi: 10.1074/jbc.M311155200

14. Bartuzi P, Billadeau DD, Favier R, Rong S, Dekker D, Fedoseienko A, et al. CCC- and WASH-mediated endosomal sorting of LDLR is required for normal clearance of circulating LDL. Nat Commun (2016) 7:10961. doi: $10.1038 /$ ncomms10961

15. Campion CG, Zaoui K, Verissimo T, Cossette S, Matsuda H, Solban N, et al. COMMD5/HCaRG Hooks Endosomes on Cytoskeleton and Coordinates EGFR Trafficking. Cell Rep (2018) 24:670-84.e677. doi: 10.1016/ j.celrep.2018.06.056 
16. Li H, Koo Y, Mao X, Sifuentes-Dominguez L, Morris LL, Jia D, et al. Endosomal sorting of Notch receptors through COMMD9-dependent pathways modulates Notch signaling. J Cell Biol (2015) 211:605-17. doi: $10.1083 /$ jcb.201505108

17. Fedoseienko A, Wieringa HW, Wisman GB, Duiker E, Reyners AK, Hofker MH, et al. Nuclear COMMD1 Is Associated with Cisplatin Sensitivity in Ovarian Cancer. PLoS One (2016) 11:e0165385. doi: 10.1371/journal.pone.0165385

18. Mu P, Akashi T, Lu F, Kishida S, Kadomatsu K. A novel nuclear complex of DRR1, F-actin and COMMD1 involved in NF-kappaB degradation and cell growth suppression in neuroblastoma. Oncogene (2017) 36:5745-56. doi: 10.1038/onc.2017.181

19. Zoubeidi A, Ettinger S, Beraldi E, Hadaschik B, Zardan A, Klomp LW, et al. Clusterin facilitates COMMD1 and I-kappaB degradation to enhance NFkappaB activity in prostate cancer cells. Mol Cancer Res (2010) 8:119-30. doi: 10.1158/1541-7786.MCR-09-0277

20. Yeh DW, Chen YS, Lai CY, Liu YL, Lu CH, Lo JF, et al. Downregulation of COMMD1 by miR-205 promotes a positive feedback loop for amplifying inflammatory- and stemness-associated properties of cancer cells. Cell Death Differ (2016) 23:841-52. doi: 10.1038/cdd.2015.147

21. Fernandez Masso JR, Oliva Arguelles B, Tejeda Y, Astrada S, Garay H, Reyes $\mathrm{O}$, et al. The Antitumor Peptide CIGB-552 Increases COMMD1 and Inhibits Growth of Human Lung Cancer Cells. J Amino Acids (2013) 2013:251398. doi: 10.1155/2013/251398

22. Li H, Burstein E. COMMD1 regulates inflammation and colitis-associated cancer progression. Oncoimmunology (2014) 3:e947891. doi: 10.4161/ 21624011.2014.947891

23. Yang SS, Li XM, Yang M, Ren XL, Hu JL, Zhu XH, et al. FMNL2 destabilises COMMD10 to activate NF-kappaB pathway in invasion and metastasis of colorectal cancer. Br J Cancer (2017) 117:1164-75. doi: 10.1038/bjc.2017.260

24. Zhan W, Wang W, Han T, Xie C, Zhang T, Gan M, et al. COMMD9 promotes TFDP1/E2F1 transcriptional activity via interaction with TFDP1 in non-small cell lung cancer. Cell Signal (2017) 30:59-66. doi: 10.1016/j.cellsig.2016.11.016

25. Dai H, Ehrentraut S, Nagel S, Eberth S, Pommerenke C, Dirks WG, et al. Genomic Landscape of Primary Mediastinal B-Cell Lymphoma Cell Lines. PLoS One (2015) 10:e0139663. doi: 10.1371/journal.pone.0139663

26. Kwiecinska A, Ichimura K, Berglund M, Dinets A, Sulaiman L, Collins VP, et al. Amplification of $2 p$ as a genomic marker for transformation in lymphoma. Genes Chromosomes Cancer (2014) 53:750-68. doi: 10.1002/gcc.22184

27. Slovak ML, Bedell V, Hsu YH, Estrine DB, Nowak NJ, Delioukina ML, et al. Molecular karyotypes of Hodgkin and Reed-Sternberg cells at disease onset reveal distinct copy number alterations in chemosensitive versus refractory Hodgkin lymphoma. Clin Cancer Res (2011) 17:3443-54. doi: 10.1158/10780432.CCR-10-1071

28. Taskinen M, Louhimo R, Koivula S, Chen P, Rantanen V, Holte H, et al. Deregulation of COMMD1 is associated with poor prognosis in diffuse large Bcell lymphoma. PLoS One (2014) 9:e91031. doi: 10.1371/journal.pone.0091031

29. Kjeldsen E. Duplication of subtelomeric regions in an adult with acute monocytic leukemia with an acquired jumping translocation involving 3q13.31-qter. Data Brief (2017) 13:675-82. doi: 10.1016/j.dib.2017.06.043

30. Mulaw MA, Krause A, Deshpande AJ, Krause LF, Rouhi A, La Starza R, et al. CALM/AF10-positive leukemias show upregulation of genes involved in chromatin assembly and DNA repair processes and of genes adjacent to the breakpoint at 10p12. Leukemia (2012) 26:1012-9. doi: 10.1038/leu.2011.307

31. Barresi V, Trovato-Salinaro A, Spampinato G, Musso N, Castorina S, Rizzarelli E, et al. Transcriptome analysis of copper homeostasis genes reveals coordinated upregulation of SLC31A1,SCO1, and COX11 in colorectal cancer. FEBS Open Bio (2016) 6:794-806. doi: 10.1002/2211-5463.12060

32. Cornella H, Alsinet C, Sayols S, Zhang Z, Hao K, Cabellos L, et al. Unique genomic profile of fibrolamellar hepatocellular carcinoma. Gastroenterology (2015) 148:806-18.e810. doi: 10.1053/j.gastro.2014.12.028

33. Peng CH, Liao CT, Peng SC, Chen YJ, Cheng AJ, Juang JL, et al. A novel molecular signature identified by systems genetics approach predicts prognosis in oral squamous cell carcinoma. PLoS One (2011) 6:e23452. doi: 10.1371/journal.pone.0023452

34. Chen BL, Yu J, Zeng ZR, Chu WK, Wong CY, Cheng YY, et al. Rosiglitazone suppresses gastric carcinogenesis by up-regulating HCaRG expression. Oncol Rep (2008) 20:1093-7. doi: 10.3892/or_00000114
35. Devlin AM, Solban N, Tremblay S, Gutkowska J, Schurch W, Orlov SN, et al. HCaRG is a novel regulator of renal epithelial cell growth and differentiation causing G2M arrest. Am J Physiol Renal Physiol (2003) 284:F753-62. doi: 10.1152/ajprenal.00252.2002

36. El Hader C, Tremblay S, Solban N, Gingras D, Beliveau R, Orlov SN, et al. HCaRG increases renal cell migration by a TGF-alpha autocrine loop mechanism. Am J Physiol Renal Physiol (2005) 289:F1273-80. doi: 10.1152/ ajprenal.00103.2005

37. Solban N, Dumas P, Gossard F, Sun Y, Pravenec M, Kren V, et al. Chromosomal mapping of HCaRG, a novel hypertension-related, calciumregulated gene. Folia Biol (Praha) (2002) 48:9-14.

38. Solban N, Jia HP, Richard S, Tremblay S, Devlin AM, Peng J, et al. HCaRG, a novel calcium-regulated gene coding for a nuclear protein, is potentially involved in the regulation of cell proliferation. J Biol Chem (2000) 275:3223443. doi: $10.1074 /$ jbc.M001352200

39. Matsuda H, Campion CG, Fujiwara K, Ikeda J, Cossette S, Verissimo T, et al. HCaRG/COMMD5 inhibits ErbB receptor-driven renal cell carcinoma. Oncotarget (2017) 8:69559-76. doi: 10.18632/oncotarget.18012

40. Matsuda H, Hamet P, Tremblay J. Hypertension-related, calcium-regulated gene (HCaRG/COMMD5) and kidney diseases: HCaRG accelerates tubular repair. J Nephrol (2014) 27:351-60. doi: 10.1007/s40620-014-0054-3

41. Matsuda H, Lavoie JL, Gaboury L, Hamet P, Tremblay J. HCaRG accelerates tubular repair after ischemic kidney injury. J Am Soc Nephrol (2011) 22:207789. doi: 10.1681/ASN.2010121265

42. Cerami E, Gao J, Dogrusoz U, Gross BE, Sumer SO, Aksoy BA, et al. The cBio cancer genomics portal: an open platform for exploring multidimensional cancer genomics data. Cancer Discov (2012) 2:401-4. doi: 10.1158/21598290.CD-12-0095

43. Gao J, Aksoy BA, Dogrusoz U, Dresdner G, Gross B, Sumer SO, et al. Integrative analysis of complex cancer genomics and clinical profiles using the cBioPortal. Sci Signal (2013) 6:pll. doi: 10.1126/scisignal.2004088

44. Gudmundsson J, Sulem P, Gudbjartsson DF, Masson G, Petursdottir V, Hardarson S, et al. A common variant at $8 \mathrm{q} 24.21$ is associated with renal cell cancer. Nat Commun (2013) 4:2776. doi: 10.1038/ncomms3776

45. Ghoussaini M, Song H, Koessler T, Al Olama AA, Kote-Jarai Z, Driver KE, et al. Multiple loci with different cancer specificities within the 8q24 gene desert. J Natl Cancer Inst (2008) 100:962-6. doi: 10.1093/jnci/djn190

46. Gudmundsson J, Sulem P, Manolescu A, Amundadottir LT, Gudbjartsson D, Helgason A, et al. Genome-wide association study identifies a second prostate cancer susceptibility variant at 8q24. Nat Genet (2007) 39:631-7. doi: 10.1038/ ng1999

47. Yeager M, Orr N, Hayes RB, Jacobs KB, Kraft P, Wacholder S, et al. Genomewide association study of prostate cancer identifies a second risk locus at 8q24. Nat Genet (2007) 39:645-9. doi: 10.1038/ng2022

48. Easton DF, Pooley KA, Dunning AM, Pharoah PD, Thompson D, Ballinger DG, et al. Genome-wide association study identifies novel breast cancer susceptibility loci. Nature (2007) 447:1087-93. doi: 10.1038/nature05887

49. Pei YL, Zhang HL, Han HG. Polymorphism of $8 \mathrm{q} 24$ rsl3281615 and breast cancer risk: a meta-analysis. Tumour Biol (2013) 34:421-8. doi: 10.1007/ s13277-012-0566-1

50. Turnbull C, Ahmed S, Morrison J, Pernet D, Renwick A, Maranian M, et al. Genome-wide association study identifies five new breast cancer susceptibility loci. Nat Genet (2010) 42:504-7. doi: 10.1038/ng.586

51. Kang JU. Chromosome $8 \mathrm{q}$ as the most frequent target for amplification in early gastric carcinoma. Oncol Lett (2014) 7:1139-43. doi: 10.3892/ ol.2014.1849

52. Ahmadiyeh N, Pomerantz MM, Grisanzio C, Herman P, Jia L, Almendro V, et al. 8q24 prostate, breast, and colon cancer risk loci show tissue-specific long-range interaction with MYC. Proc Natl Acad Sci U S A (2010) 107:97426. doi: $10.1073 /$ pnas.0910668107

53. Hutter CM, Slattery ML, Duggan DJ, Muehling J, Curtin K, Hsu L, et al. Characterization of the association between $8 \mathrm{q} 24$ and colon cancer: geneenvironment exploration and meta-analysis. BMC Cancer (2010) 10:670. doi: 10.1186/1471-2407-10-670

54. Zanke BW, Greenwood CM, Rangrej J, Kustra R, Tenesa A, Farrington SM, et al. Genome-wide association scan identifies a colorectal cancer susceptibility locus on chromosome 8q24. Nat Genet (2007) 39:989-94. doi: 10.1038/ng2089 
55. Han J, Zhou J, Yuan H, Zhu L, Ma H, Hang D, et al. Genetic variants within the cancer susceptibility region 8q24 and ovarian cancer risk in Han Chinese women. Oncotarget (2017) 8:36462-8. doi: 10.18632/oncotarget.16861

56. White KL, Sellers TA, Fridley BL, Vierkant RA, Phelan CM, Tsai YY, et al. Variation at $8 \mathrm{q} 24$ and $9 \mathrm{p} 24$ and risk of epithelial ovarian cancer. Twin Res Hum Genet (2010) 13:43-56. doi: 10.1375/twin.13.1.43

57. Kiemeney LA, Thorlacius S, Sulem P, Geller F, Aben KK, Stacey SN, et al. Sequence variant on $8 \mathrm{q} 24$ confers susceptibility to urinary bladder cancer. Nat Genet (2008) 40:1307-12. doi: 10.1038/ng.229

58. Crowther-Swanepoel D, Broderick P, Di Bernardo MC, Dobbins SE, Torres $\mathrm{M}$, Mansouri M, et al. Common variants at 2q37.3, 8q24.21, 15q21.3 and 16 q24.1 influence chronic lymphocytic leukemia risk. Nat Genet (2010) 42:132-6. doi: 10.1038/ng.510

59. Beroukhim R, Mermel CH, Porter D, Wei G, Raychaudhuri S, Donovan J, et al. The landscape of somatic copy-number alteration across human cancers. Nature (2010) 463:899-905. doi: 10.1038/nature08822

60. Moore SR, Persons DL, Sosman JA, Bobadilla D, Bedell V, Smith DD, et al. Detection of copy number alterations in metastatic melanoma by a DNA fluorescence in situ hybridization probe panel and array comparative genomic hybridization: a southwest oncology group study (S9431). Clin Cancer Res (2008) 14:2927-35. doi: 10.1158/1078-0432.CCR-07-4068

61. Nowak NJ, Miecznikowski J, Moore SR, Gaile D, Bobadilla D, Smith DD, et al. Challenges in array comparative genomic hybridization for the analysis of cancer samples. Genet Med (2007) 9:585-95. doi: 10.1097/GIM.0b013e3181461c4a

62. Hirashima K, Migita T, Sato S, Muramatsu Y, Ishikawa Y, Seimiya H. Telomere length influences cancer cell differentiation in vivo. Mol Cell Biol (2013) 33:2988-95. doi: 10.1128/MCB.00136-13

63. Herranz N, Gil J. Mechanisms and functions of cellular senescence. J Clin Invest (2018) 128:1238-46. doi: 10.1172/JCI95148

64. Campisi J. Cellular Senescence, Aging and Cancer. Sci World J (2001) 1:65. doi: 10.1100/tsw.2001.106

65. Pucci F, Gardano L, Harrington L. Short telomeres in ESCs lead to unstable differentiation. Cell Stem Cell (2013) 12:479-86. doi: 10.1016/j.stem.2013.01.018

66. Westhoff JH, Schildhorn C, Jacobi C, Homme M, Hartner A, Braun H, et al. Telomere shortening reduces regenerative capacity after acute kidney injury. J Am Soc Nephrol (2010) 21:327-36. doi: 10.1681/ASN.2009010072

67. Holzmann K, Blin N, Welter C, Zang KD, Seitz G, Henn W. Telomeric associations and loss of telomeric DNA repeats in renal tumors. Genes Chromosomes Cancer (1993) 6:178-81. doi: 10.1002/gcc.2870060308

68. Mehle C, Ljungberg B, Roos G. Telomere shortening in renal cell carcinoma. Cancer Res (1994) 54:236-41.

69. Fiedler W, Dahse R, Schlichter A, Junker K, Kosmehl H, Ernst G, et al. Telomerase activity and telomere length in different areas of renal cell carcinoma. Int J Oncol (1996) 9:1227-32. doi: 10.3892/ijo.9.6.1227

70. Dahse R, Fiedler W, Junker K, Schlichter A, Schubert J, Claussen U. Telomerase activity and telomere lengths: alterations in renal cell carcinomas. Kidney Int (1999) 56:1289-90. doi: 10.1046/j.1523-1755.1999.00688.x

71. Morais M, Dias F, Teixeira AL, Medeiros R. Telomere Length in Renal Cell Carcinoma: The Jekyll and Hyde Biomarker of Ageing of the Kidney. Cancer Manag Res (2020) 12:1669-79. doi: 10.2147/CMAR.S211225

72. Svenson U, Ljungberg B, Roos G. Telomere length in peripheral blood predicts survival in clear cell renal cell carcinoma. Cancer Res (2009) 69:2896-901. doi: 10.1158/0008-5472.CAN-08-3513

73. Pal D, Sharma U, Khajuria R, Singh SK, Kakkar N, Prasad R. Augmented telomerase activity, reduced telomere length and the presence of alternative lengthening of telomere in renal cell carcinoma: plausible predictive and diagnostic markers. Gene (2015) 562:145-51. doi: 10.1016/j.gene.2015.02.079

74. Wills LP, Schnellmann RG. Telomeres and telomerase in renal health. J Am Soc Nephrol (2011) 22:39-41. doi: 10.1681/ASN.2010060662

75. McNally EJ, Luncsford PJ, Armanios M. Long telomeres and cancer risk: the price of cellular immortality. J Clin Invest (2019) 129:3474-81. doi: 10.1172/JCI120851

76. Kim NW, Piatyszek MA, Prowse KR, Harley CB, West MD, Ho PL, et al. Specific association of human telomerase activity with immortal cells and cancer. Science (1994) 266:2011-5. doi: 10.1126/science.7605428

77. Recagni M, Bidzinska J, Zaffaroni N, Folini M. The Role of Alternative Lengthening of Telomeres Mechanism in Cancer: Translational and Therapeutic Implications. Cancers (Basel) (2020) 12(4):949. doi: 10.3390/cancers12040949
78. Rampazzo E, Bertorelle R, Serra L, Terrin L, Candiotto C, Pucciarelli S, et al. Relationship between telomere shortening, genetic instability, and site of tumour origin in colorectal cancers. Br J Cancer (2010) 102:1300-5. doi: 10.1038/sj.bjc.6605644

79. Robin JD, Ludlow AT, Batten K, Magdinier F, Stadler G, Wagner KR, et al. Telomere position effect: regulation of gene expression with progressive telomere shortening over long distances. Genes Dev (2014) 28:2464-76. doi: $10.1101 / \mathrm{gad} .251041 .114$

80. Robin JD, Ludlow AT, Batten K, Gaillard MC, Stadler G, Magdinier F, et al. SORBS2 transcription is activated by telomere position effect-over long distance upon telomere shortening in muscle cells from patients with facioscapulohumeral dystrophy. Genome Res (2015) 25:1781-90. doi: $10.1101 /$ gr.190660.115

81. Kim W, Shay JW. Long-range telomere regulation of gene expression: Telomere looping and telomere position effect over long distances (TPEOLD). Differentiation (2018) 99:1-9. doi: 10.1016/j.diff.2017.11.005

82. Kim W, Ludlow AT, Min J, Robin JD, Stadler G, Mender I, et al. Regulation of the Human Telomerase Gene TERT by Telomere Position Effect-Over Long Distances (TPE-OLD): Implications for Aging and Cancer. PLoS Biol (2016) 14:e2000016. doi: 10.1371/journal.pbio.2000016

83. Lou Z, Wei J, Riethman H, Baur JA, Voglauer R, Shay JW, et al. Telomere length regulates ISG15 expression in human cells. Aging (Albany NY) (2009) 1:608-21. doi: 10.18632/aging.100066

84. Pedram M, Sprung CN, Gao Q, Lo AW, Reynolds GE, Murnane JP. Telomere position effect and silencing of transgenes near telomeres in the mouse. Mol Cell Biol (2006) 26:1865-78. doi: 10.1128/MCB.26.5.1865-1878.2006

85. Zhou BO, Wang SS, Zhang Y, Fu XH, Dang W, Lenzmeier BA, et al. Histone $\mathrm{H} 4$ lysine 12 acetylation regulates telomeric heterochromatin plasticity in Saccharomyces cerevisiae. PLoS Genet (2011) 7:e1001272. doi: 10.1371/ journal.pgen.1001272

86. Weuts A, Voet T, Verbeeck J, Lambrechts N, Wirix E, Schoonjans L, et al. Telomere length homeostasis and telomere position effect on a linear human artificial chromosome are dictated by the genetic background. Nucleic Acids Res (2012) 40:11477-89. doi: 10.1093/nar/gks926

87. Buxton JL, Suderman M, Pappas JJ, Borghol N, McArdle W, Blakemore AI, et al. Human leukocyte telomere length is associated with DNA methylation levels in multiple subtelomeric and imprinted loci. Sci Rep (2014) 4:4954. doi: 10.1038/srep04954

88. Tennen RI, Bua DJ, Wright WE, Chua KF. SIRT6 is required for maintenance of telomere position effect in human cells. Nat Commun (2011) 2:433. doi: $10.1038 /$ ncomms 1443

89. Anderson MZ, Gerstein AC, Wigen L, Baller JA, Berman J. Silencing is noisy: population and cell level noise in telomere-adjacent genes is dependent on telomere position and sir2. PLoS Genet (2014) 10:e1004436. doi: 10.1371/ journal.pgen.1004436

90. Campisi J. Cancer, aging and cellular senescence. In Vivo (2000) 14:183-8. doi: 10.1146/annurev-physiol-030212-183653

91. Cristofalo VJ, Pignolo RJ. Replicative senescence of human fibroblast-like cells in culture. Physiol Rev (1993) 73:617-38. doi: 10.1152/physrev.1993.73.3.617

92. Cristofalo VJ, Pignolo RJ. Molecular markers of senescence in fibroblast-like cultures. Exp Gerontol (1996) 31:111-23. doi: 10.1016/0531-5565(95)02018-7

93. Hayflick L. The Limited in Vitro Lifetime of Human Diploid Cell Strains. Exp Cell Res (1965) 37:614-36. doi: 10.1016/0014-4827(65)90211-9

94. Xu D, Takeshita F, Hino Y, Fukunaga S, Kudo Y, Tamaki A, et al. miR-22 represses cancer progression by inducing cellular senescence. J Cell Biol (2011) 193:409-24. doi: 10.1083/jcb.201010100

Conflict of Interest: The authors declare that the research was conducted in the absence of any commercial or financial relationships that could be construed as a potential conflict of interest.

Copyright (๑) 2021 Campion, Verissimo, Cossette and Tremblay. This is an open-access article distributed under the terms of the Creative Commons Attribution License (CC BY). The use, distribution or reproduction in other forums is permitted, provided the original author(s) and the copyright owner(s) are credited and that the original publication in this journal is cited, in accordance with accepted academic practice. No use, distribution or reproduction is permitted which does not comply with these terms. 